\title{
Association of FMRP with Ribosomal Precursor Particles in the Nucleolus
}

\author{
Rob Willemsen, Carola Bontekoe, Filippo Tamanini, Hans Galjaard, \\ Andre Hoogeveen, and Ben Oostra ${ }^{1}$ \\ MGC-Department of Clinical Genetics, Erasmus University, Rotterdam, The Netherlands
}

Received June 20, 1996

\begin{abstract}
The fragile $\mathrm{X}$ syndrome, one of the most common forms of inherited mental retardation, is caused by an expansion of a polymorphic CGG repeat upstream the coding region of the FMR1 gene. These expansions are associated with hypermethylation of the FMR1 gene, which results in the absence of the gene product, the FMR1 protein (FMRP). The physiological function of FMRP remains to be determined. We studied the ultrastructural localization of FMRP at the electron microscopical level using the immunogold technique. FMRP is associated with ribosomes attached to the endoplasmic reticulum and with ribosomes free in the cytoplasm. In addition, FMRP is found in the nucleus where the protein is associated with the granular component of the nucleolus. The cellular function of FMRP is hypothesized in relation to its subcellular distribution. (ㅇ 1996 Academic Press, Inc.
\end{abstract}

Fragile $\mathrm{X}$ syndrome is characterized by a large variability in clinical presentation, including mental retardation, macroorchidism and facial abnormalities as the main characteristics in affected males ${ }^{1}$. The most common mutation found in fragile $\mathrm{X}$ patients is an unstable expansion of a CGG repeat in the first exon of the FMRl gene $e^{2-4}$. This expansion in patients results in hypermethylation of the $\mathrm{CpG}$ island in front of the FMRI gene and as a consequence no transcription and thus no translation of the FMRI gene occurs ${ }^{5-7}$. The absence of functional FMR1 Protein (FMRP), the protein product of the FMR1 gene, is the primary defect of the fragile $\mathrm{X}$ syndrome ${ }^{8,9}$.

FMRP is expressed in many tissues with the most abundant expression in specific neurons of the central nervous system and in early spermatogonia ${ }^{8-12}$. Immunocytochemical studies at the light microscopic level have shown that FMRP is found predominantly in the cytoplasm ${ }^{8,9}$. However, in some studies a nuclear localization of the protein in specific cell types have been reported $^{8,13}$. One of these studies reported a nuclear localization for one isoform of FMRP in transfected COS-cells using a construct that exclude exon 14 of the FMR1 gene ${ }^{13}$.

FMRP contains two KH domains and an RGG box ${ }^{14,15}$. Both sequence motifs are present in many RNA binding proteins. RNA binding properties of FMRP has been demonstrated too ${ }^{14,15}$. RNA binding studies in cells from a fragile $\mathrm{X}$ patient with a missense mutation in one of the two $\mathrm{KH}$ domains resulted in FMRP with reduced RNA binding capacity, which is consistent with the hypothesis that RNA binding is essential in mediating FMRP function ${ }^{16-18}$.

Additional to its RNA binding capacity an association in vitro with ribosomes has recently been described and it has been suggested that this binding occurs via rRNA ${ }^{19-20}$. However, all these results were obtained solely by in vitro studies. An in vivo RNA target(s) or other cellular components for FMRP has not been identified, yet.

\footnotetext{
${ }^{1}$ To whom correspondence should be addressed at the Dept of Clinical Genetics, Erasmus University, P.O. Box 1738, 3000 DR Rotterdam, The Netherlands. Fax: 31-10-4087200; E-mail: Oostra@kgen.fgg.eur.nl.
} 
Since, the specific function of FMRP in the cell is still poorly understood, we investigated the subcellular distribution of FMRP. Here, we describe the in vivo association with cellular structures of FMRP in transfected COS-cells. Our immunoelectron microscopic studies illustrate that FMRP is associated with free ribosomes and with ribosomes that are attached to the membrane of the endoplasmic reticulum. Furthermore, we show that FMRP is already present in the granular component of the nucleolus, which contains maturing ribosomal precursor particles.

\section{MATERIALS AND METHODS}

DNA constructs. A 3,765 cDNA clone of FMRI was cloned in the EcoRI site of the eukaryotic expression vector $\mathrm{pSG}^{23}$. In this construct the expression of FMRP is controlled by the SV40 promoter. The construct contains a $\beta$ globin intron and a polyadenylation signal. Transfections with this construct will result in a protein of $74 \mathrm{kDa}^{8}$. The FMRI missing exon 14 clone was generated as described before 13 and the construct was cloned in the expression vector pcDNAI/AMP (Invitrogen), which is controlled by the CMV promotor.

Transfections. COS-cells were cultured in 1X DMEM $+10 \% \mathrm{FCS}$ at $37^{\circ} \mathrm{C}$ and $10 \% \mathrm{CO}_{2}$. Cells were seeded and cultured for 24 hours. Transfections were performed as described in the protocol provided with the lipofectamine reagent (Gibco-BRL), for transfections $2 \mu \mathrm{g}$ DNA and $20 \mu$ l lipofectamine were used per $2 \times 10^{4}$ seeded cells. After transfection the cells were cultured for 48 hours. Subsequently, cells used for light microscopy were transferred to coverslips and cultured for another 24 hours. Cells used for electronmicroscopy were fixed 72 hours after transfection.

Immunocytochemistry. For light microscopy, cells were fixed in $0.1 \mathrm{M}$ phosphate buffered saline (PBS) containing $3 \%$ paraformaldehyde $(\mathrm{pH} 7.3$ ) for 10 minutes at room temperature followed by a permeabilization step in $100 \%$ methanol for 20 minutes. FMRP was localized using an indirect immunoperoxidase technique. In the first step we used a monoclonal antibody against FMRP $^{9}$ and in the second step a rabbit anti-mouse immunoglobulins conjugated with peroxidase (DAKO) was applied. Enzyme activity was visualized using DAB (Sigma) as substrate. Endogenous peroxidase activity was blocked by pre-treatment of the cells with $3 \% \mathrm{H}_{2} \mathrm{O}_{2}$ after the permeabilization step. Cells were counterstained with Heamatoxylin and mounted with aquamount.

For electronmicroscopy, cells were fixed in $0.1 \mathrm{M} \mathrm{PBS}$, containing $1 \%$ acrolein and $0.4 \%$ glutaraldehyde for 1 hour at room temperature. Subsequently, cells were embedded in Lowicryl K4M according to a standard protocol ${ }^{24}$. Ultrathin sections were cut with a LKB Nova ultratome and immuno-incubated for FMRP with the monoclonal antibody ${ }^{9}$. Antigen-antibody complexes were visualized using a second incubation step with goat anti-mouse immunoglobulins conjugated with $10 \mathrm{~nm}$ colloidal gold particles (AURION). Sections were stained with uranylacetate and leadnitrate and examined in a Philips CM100 at $80 \mathrm{kV}$.

\section{RESULTS}

Thus far, immunocytochemical studies of FMRP in transfected COS-cells were based on the use of immuno-fluorescence microscopy. The resolution of this technique is limited, which makes conclusions about association of FMRP with specific cell organelles difficult. Therefore, in the past only a discrimination between cytoplasmic or nuclear localization could be made.

In a first attempt to enhance the immunocytochemical signal at the light microscopic level, we used an indirect immunoperoxidase technique to detect FMRP in transfected COS-cells. Figure 1 shows the FMRP distribution in COS-cells transfected with a full length cDNA construct and a construct missing exon 14 of the FMRl gene. Normal FMRP was predominantly found in the cytoplasm, often in large aggregates. However, in some cells we could detect FMRP in the nucleus, in close association with the nucleolus (Fig. 1A). In contrast, the cellular localization of FMRP with the internal deletion of exon 14 revealed predominantly a nuclear staining, with the exclusion of the nucleolus (Fig. 1B).

FIG. 1. Cellular localization of FMRP, using an indirect immunoperoxidase technique in COS-cells transfected with a full length cDNA for FMRI (A) and a construct missing exon 14 sequences of the $F M R l$ gene (B). The highest expression of normal FMRP is found in the cytoplasm, but also in the nucleus a clear labelling can be detected. Note that the reaction product (brown) in the cytoplasm is very often found in large aggregates. The expression of FMRP, excluding exon 14, shows a different labelling pattern. Most of the reaction product is present in the nucleus and only a minor fraction was found in the cytoplasm. The reaction product is virtually absent in the nucleolus. 

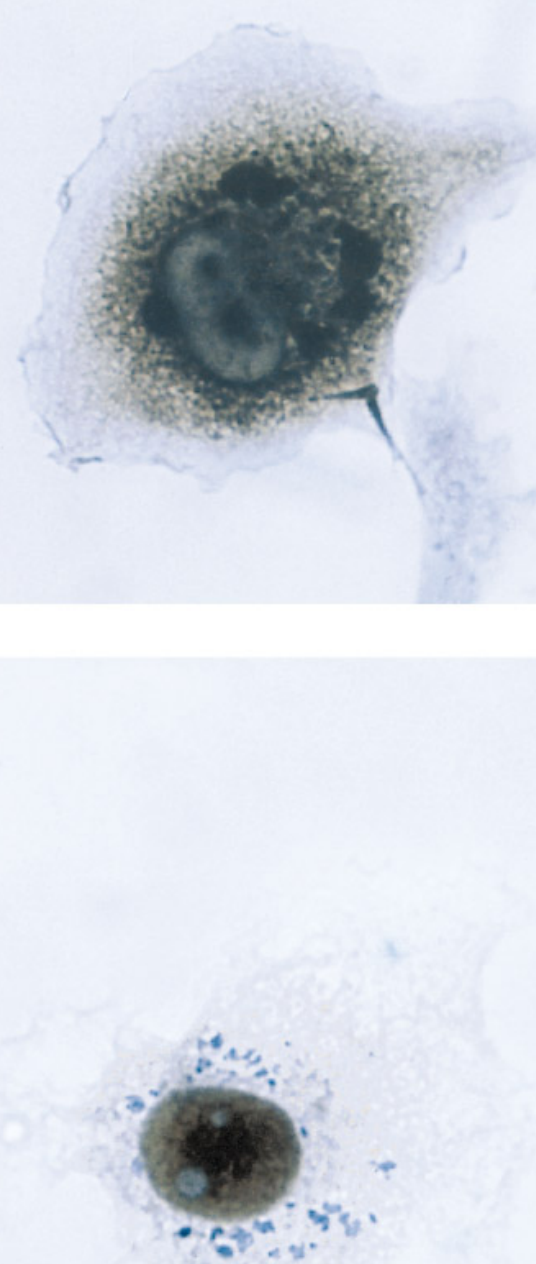

B 
We performed immunoelectron microscopy to study the subcellular distribution of FMRP in vivo. The gold particles in Figure 2 illustrate the subcellular localization of FMRP in these transfected COS-cells. In the cytoplasm, FMRP was associated with ribosomes bound to the endoplasmic reticulum (ER) membrane (Figs. 2A and 2B) and with ribosomes free in the cytosol (Fig. 2C). Very often we could observe a concentration of ribosomes close to the ER membrane. Apparently, these fast dividing COS-cells are active in protein production. This phenomenon was also seen in COS-cells that were not transfected with FMRI (Fig. 2D). The latter suggests that overexpression of FMRP does not play a role in this concentration of ribosomes. The specificity of the labelling procedure is demonstrated by the absence of gold particles in COS-cells that were not transfected with FMR1, but completed the transfection procedure (Fig. 2D).

Interestingly, beside a cytoplasmic localization FMRP could also be demonstrated in the granular component of the nucleolus (Fig. 2E), which contains maturing ribosomal precursor particles. The distribution of gold particles in these transfected COS-cells demonstrates that most of the FMRP is present in the cytoplasm and only a minor fraction is present in the nucleus.

\section{DISCUSSION}

The discovery of the gene defect in the FMR1 gene has led to a better understanding of the molecular basis of the fragile $\mathrm{X}$ mental retardation syndrome. However, the knowledge about the function of FMRP, the protein product of the FMR1 gene, in the cell is still limited. In this immunoelectron microscopic study we report the actual in vivo localization of FMRP. We found FMRP associated with ribosomes that were free in the cytoplasm and with ribosomes that were attached to the ER membrane. The resolution of our immunocytochemical studies is not high enough to demonstrate the association of FMRP with the ribosomal 60S subunit as was suggested by Khandjian et al. on the basis of their in vitro experiments ${ }^{19}$.

Surprisingly, we could demonstrate the presence of FMRP in the nucleolus where the protein was associated with the granular component, which contains maturing ribosomal precursor particles. Since, proteins above the size of $60 \mathrm{kDa}$ can enter the nucleus only in an active way $^{21}$ this would implicate that FMRP, on the basis of its molecular weight of $67-80 \mathrm{kDa}$, is also dependent on such a signal dependent transport across the nuclear pore. Expression studies demonstrated that the N-terminus of FMRP (spanning exon 1-8) contains signal(s) or binding motifs to mediate the protein to the nucleus ${ }^{13}$. However, the majority of FMRP in the normal in vivo situation is found in the cytoplasm ${ }^{8,9}$ (Figure 1A). A possible explanation for this discrepancy came from studies on an exon 14 splice variant ${ }^{13}$ (Figure 1B). This splice variant was found predominantly in the nucleus. It was proposed that a cytoplasmic retention signal was present within exon 14 of the FMRl gene. Recently, it was shown that FMRP contains a nuclear export signal (NES) (Warren, personal communication). They found that sequences present in exon 14 are able to transport a reporter protein from the nucleus to the cytoplasm. The presence of both these signals (NLS and NES) suggests that FMRP may shuttle between the nucleus and the cytoplasm.

FIG. 2. Subcellular localization of FMRP, using an indirect immunogold labelling technique in COS-cells transfected with a full length cDNA. FMRP is found in association with ribosomes that are bound to the endoplasmic reticulum membrane (A and $\mathrm{B}$ ) and in association with free ribosomes in the cytoplasm (C). In these COS-cells we notice very often a concentration of ribosomes lining the endoplasmic reticulum membrane (arrows in B, C and D). Note that these aggregates are also found in untransfected cells (D). Furthermore, FMRP is localized in the nucleolus of transfected cells (E). The arrows indicate the nuclear membrane. $\mathrm{L}=$ Lysosome; $\mathrm{M}=\mathrm{Mitochondrion} ; \mathrm{N}=\mathrm{Nucleus}$; $\mathrm{C}=$ Cytoplasm; $\mathrm{R}=$ Rough endoplasmic reticulum; $\mathrm{Nu}=$ Nucleolus . 

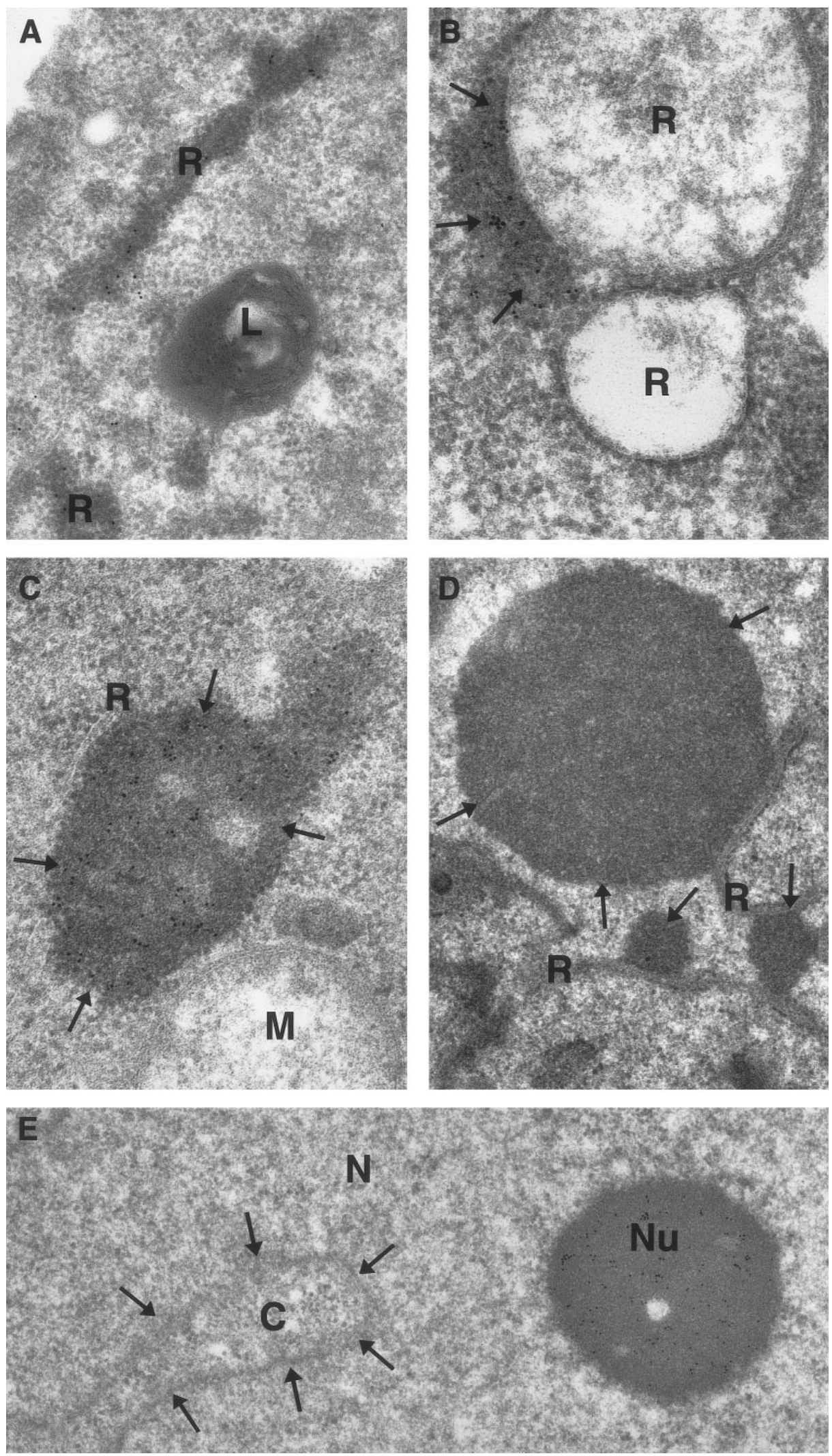
These observations and our data that FMRP is present in the nucleolus would argue for the hypothesis that after synthesis in the cytoplasm active transport of FMRP to the nucleus, either via an NLS or via the interaction of the N-terminus with a nuclear component, takes place. In the nucleus an association with maturing ribosomal precursor particles, located in the nucleolus, occurs. It remains unclear whether FMRP plays an active role in targeting ribosomal precursor particles out of the nucleus or that FMRP is a just a ribosomal protein leaving the nucleus in a passive way, mediated by maturing ribosomal particles. The latter is most likely, since in cells from fragile $\mathrm{X}$ patients, lacking FMRP, a normal transport of ribosomes from the nucleus to the cytoplasm occurs.

On the other hand, the RNA binding properties of FMRP and the in vitro association with ribosomes led to different proposals for a theoretical function for FMRP. One possibility is that FMRP plays a regulatory role in the translational machinery of proteins by mediating transport of mRNA. There are two arguments against this hypothesis. First, our finding that FMRP is associated with the nucleolus, indicating a binding to rRNA instead of mRNA. Second, the fact that the small ribosomal subunit first binds a mRNA molecule and subsequently associates with the large ribosomal subunit, which makes the association of FMRP with the large ribosomal subunit secondary for a role in mRNA binding. In this respect, Tamanini et al. ${ }^{20}$ already suggested the association of FMRP with ribosomes via rRNA in their in vitro studies.

Our study suggests a nuclear role for FMRP, like the many ribosomal proteins that are imported from the cytoplasm and subsequent packaged into ribonucleoprotein particles. Indeed, FMRP shuttles between the nucleus and the cytoplasm. In both compartments FMRP is bound to ribosomes, which is characteristic for ribosomal proteins. Although ribosomes contain a large number of proteins, the function of many of them is unknown. It is thought that they enhance the function of the ribosomes.

However, in this view it is difficult to explain that the absence of widely expressed FMRP causes the "limited" clinical features observed in fragile X syndrome. The identification of two human genes, FXR1 and FXR2, which show a high homology with the FMR1 gene shed a new light on a possible function of FMRP. Both, FXR1 and FXR2, can form homo- and heteromultimers with FMRP and like FMRP they also have RNA binding properties. Interestingly, FXR1 is not expressed in human brain ${ }^{22}$ (Hoogeveen, unpublished results). Perhaps the impossibility of FXR2 protein to form heteromultimers in vivo by the absence of FMRP and FXR1 proteins in neurons from affected males is responsible for the mental retardation in these patients. Alternatively, a misrouting of the FXR2 protein because of the lack of FMRP expression and subsequent targeting to the nucleus and/or out of the nucleus may cause the dysfunction of central nervous system neurons.

Clearly, extensive studies to validate this hypothesis are necessary. The biochemical basis for the interaction between FMRP and the two homologs FXR1 and FXR2 and the in vivo RNA target(s) for FMRP are just two examples of further investigations. The answers to these questions may result in more knowledge about the cellular function of FMRP and the underlying cause of the characteristic phenotype of the fragile $\mathrm{X}$ syndrome.

\section{ACKNOWLEDGMENTS}

The excellent photography of Ton de Vries Lentsch and Ruud Koppenol is greatly appreciated. This research was supported by grants from the Netherlands Organization of Scientific Research (C.B.) and from Telethon-Italy (F.T.). We thank S. Warren (Atlanta) for releasing data prior to publication, Dr. J. L. Mandel and Dr. D. Devys for giving the exon 14 minus FMR1 clone, and J. Stahl (Berlin) for helpful discussions.

\section{REFERENCES}

1. Hagerman, R. J. (1991) in Physical and Behavioral Phenotype (Hagerman, R. J., and Silverman, A. C., Eds.), pp. 1-68, John Hopkins Univ. Press, Baltimore/London. 
2. Verkerk, A. J., Pieretti, M., Sutcliffe, J. S., Fu, Y. H., Kuhl, D. P., Pizzuti, A., Reiner, O., Richards, S., Victoria, M. F., Zhang, F. P., Eussen, B. E., Van Ommen, G. J. B., Blonden, L. A. J., Riggins, G. J., Chastain, J. L., Kunst, C. B., Galjaard, H., Caskey, C. T., Nelson, D. L., Oostra, B. A., and Warren, S. T. (1991) Cell 65, $905-$ 914.

3. Oberlé, I., Rousseau, F., Heitz, D., Kretz, C., Devys, D., Hanauer, A., Boue, J., Bertheas, M. F., and Mandel, J. L. (1991) Science 252, 1097-1102.

4. Oostra, B. A., and Willems, P. J. (1995) Bioessays 17, 941-947.

5. Vincent, A., Heitz, D., Petit, C., Kretz, C., Oberlé, I., and Mandel, J. L. (1991) Nature 349, 624-626.

6. Pieretti, M., Zhang, F. P., Fu, Y. H., Warren, S. T., Oostra, B. A., Caskey, C. T., and Nelson, D. L. (1991) Cell 66, $817-822$.

7. Sutcliffe, J. S., Nelson, D. L., Zhang, F., Pieretti, M., Caskey, C. T., Saxe, D., and Warren, S. T. (1992) Hum Mol Genet 1, 397-400.

8. Verheij, C., Bakker, C. E., de-Graaff, E., Keulemans, J., Willemsen, R., Verkerk, A. J., Galjaard, H., Reuser, A. J., Hoogeveen, A. T., and Oostra, B. A. (1993) Nature 363, 722-724.

9. Devys, D., Lutz, Y., Rouyer, N., Bellocq, J. P., and Mandel, J. L. (1993) Nature Genet 4, 335-340.

10. Hinds, H. L., Ashley, C. T., Sutcliffe, J. S., Nelson, D. L., Warren, S. T., Housman, D. E., and Schalling, M. (1993) Nature Genet 3, 36-43.

11. Bächner, D., Steinbach, P., Wöhrle, D., Just, W., Vogel, W., Hameister, H., Manca, A., and Poustka, A. (1993) Nature Genet 4, 115-116.

12. De Graaff, E., Willemsen, R., Zhong, N., De Die-Smulders, C. E. M., Brown, W. T., Freling, G., and Oostra, B. A. (1995) Am J Hum Genet 57, 609-618.

13. Sittler, A., Devys, D., Weber, C., and Mandel, J.-L. (1996) Hum Mol Genet 5, 95-102.

14. Siomi, H., Siomi, M. C., Nussbaum, R. L., and Dreyfuss, G. (1993) Cell 74, 291-298.

15. Ashley, C., Jr., Wilkinson, K. D., Reines, D., and Warren, S. T. (1993) Science 262, 563-568.

16. De Boulle, K., Verkerk, A. J., Reyniers, E., Vits, L., Hendrickx, J., Van Roy, B., Van den Bos, F., de Graaff, E., Oostra, B. A., and Willems, P. J. (1993) Nature Genet 3, 31-35.

17. Siomi, H., Choi, M., Siomi, M. C., Nussbaum, R. L., and Dreyfuss, G. (1994) Cell 77, 33-39.

18. Verheij, C., De Graaff, E., Bakker, C. E., Willemsen, R., Willems, P. J., Meijer, N., Galjaard, H., Reuser, A. J. J., Oostra, B. A., and Hogeveen, A. T. (1995) Hum Mol Genet 4, 895-901.

19. Khandjian, E., Corbin, F., Woerly, S., and Rousseau, F. (1996) Nature Genet 12, 91-93.

20. Tamanini, F., Meijer, N., Verheij, C., Willems, P. J., Galjaard, H., Oostra, B. A., and Hoogeveen, A. T. (1996) Hum Mol Genet 5, 809-813.

21. Gorlich, D., and Mattaj, I. W. (1996) Science 271, 1513-1518.

22. Coy, J. F., Sedlacek, Z., Bachner, D., Hameister, H., Joos, S., Lichter, P., Delius, H., and Poustka, A. (1995) Hum Mol Genet 4, 2209-2218.

23. Green, S., Isseman, I., and Sheer, E. (1988) Nucleic Acids Res 16, 369.

24. Armbruster, B. L., Carleman, E., and Chiovetti, R. (1982) J. Microsc 126, 77-85. 